\title{
Penerapan Metode Simple Additivie Weighting Untuk Mengefektifkan Penilaian Kinerja Karyawan
}

\author{
Neni Mulyani*, Jeperson Hutahaean \\ Prodi Sistem Informasi, STMIK Royal Kisaran, Kisaran, Indonesia \\ Email: 1,"neni.muliani@gmail.com, ${ }^{2}$ jepersonhutahean@gmail.com \\ Email Penulis Korespondensi: neni.muliani@gmail.com
}

\begin{abstract}
Abstrak-Pada penelitian ini penerapan metode Simple Additive Weighting (SAW) di butuhkan untuk menghasilkan nilai preferensi terhadap 16 data karyawan yang dijadikan alternatif penilaian kinerja karyawan. Penerapan metode SAW dalam hal ini juga bertujuan untuk meningkatkan hasil keputusan yang di buat oleh manager. Sehingga dalam satu periode penilaian kinerja atas karyawan pada akhir tahun manager dapat memberikan keputusan terhadap karyawan yang memiliki kinerja sangat baik $(0,80-1,00)$ hingga karyawan yang memiliki kinerja buruk. Hasil nilai preferensi dari perhitungan menggunakan metode SAW akan dibuat dalam bentuk range penilaian, sehingga atas dasar nilai range tersebut manager dapat memberikan penilaian kinerja karyawan.
\end{abstract}

Kata Kunci: Penilaian; Kinerja Karyawan; Efektifitas; Informasi; SAW

\begin{abstract}
In this study, the application of the Simple Additive Weighting (SAW) method is needed to generate preference values for 16 employee data which is used as an alternative employee performance appraisal. The application of the SAW method in this case also aims to improve the results of decisions made by managers. So that in one period of performance appraisal of employees at the end of the year the manager can make decisions on employees who have very good performance $(0.80-1.00)$ to employees who have poor performance. The results of the preference value from the calculation using the SAW method will be made in the form of an assessment range, so that based on the value of the range the manager can provide an employee performance assessment.
\end{abstract}

Keywords: Assessment; Employee performance; Effectiveness; Information; SAW

\section{PENDAHULUAN}

Perkembangan teknologi yang semakin pesat, perusahaan dituntut untuk dapat memberikan pelayanan terbaik kepada konsumen dan mitra bisnisnya. Hal ini menyebabkan sumber daya manusia dituntut untuk menampilkan performa yang terbaik dengan demikian perusahaan mampu bersaing dengan para kompetitornya. Sumber daya manusia memiliki peranan yang sangat vital bagi kelangsungan hidup perusahaan. Pengolahan dalam penilaian kinerja karyawan, dapat memberikan informasi kepada manajer terhadap perilaku karyawan yang berkaitan dengan pekerjaannya. Penilai kinerja karyawan juga dapat digunakan sebagai penetapan kompensasi atau pemberian reward, promosi kenaikan jabatan karyawan dan lainnya.

Penilaian kinerja karyawan merupakan kegiatan yang sangat penting dalam manajemen kinerja. Adanya proses ini, membuat karyawan untuk dapat terus mengembangankan keahlian, produktivitas dan disertai dengan loyalitasnya selaku karyawan pada perusahaan. Namun permasalahan yang sering terjadi pada perusahaan, yakni perusahaan sering dinilai tidak memberikan hasil yang objektif terhadap penilaian kinerja karyawan. Untuk itu butuhkan sistem berbasis komputer yang dapat memberikan dukungan terhadap penilaian kinerja karyawan sehingga hasilnya menjadi lebih baik dan efektif. Sistem ini dikenal dengan nama sistem pendukung keputusan (DSS). Sistem Pendukung keputusan merupakan sistem buatan manusia yang menggunakan komputer sebagai alat bantu dalam pemrosesan data sehingga mampu menyelesaikan permasalahan yang dihadapi oleh manajer[1]-[4]. Penerapan metode pada sistem pendukung keputusan akan mampu memberikan hasil menjadi lebih efektif. Diantara metode-metode sederhana yang sangat membantu proses pengolahan data tersebut yaitu Simple Additive Weighting (SAW), Weighted Product (WP), MOORA, ELECTRE, VIKOR[5]-[7].

Hingga saat ini penerapan sistem pendukung keputusan sangat banyak di lakukan untuk membantu dalam memberikan dukungan keputusan bagi manajemen, seperti yang dilakukan Supriyanto (2020) untuk menghitung keputusan pemberian kredit menggunakan ARAS[8], Dodi Siregar (2018) menggunakan VIKOR untuk permasalahan berbasis multikriteria[9], Mesran (2019) menggunakan metode VIKOR dalam penentuan penerimaan reward berdasarkan kinerja karyawan[10], Sutarno (2019) menerapkan metode MOORA untuk mengefektifkan keputusan terhadap lokasi penjualan[11].

Pada penelitian ini penulis menggunakan metode Simple Additive Weighting (SAW) untuk mengolah datadata karyawan sehingga mendapatkan nilai kinerja. Metode SAW merupakan suatu metode yang bekerja berdasarkan penjumlahan terhadap matrik terbobot[12]-[17]. Hasil perhitungan preferensi akan dijadikan sebagai nilai kinerja dan akan dilakukan pemeringkatan sehingga diperoleh karyawan yang memiliki kinerja sangat baik, baik, cukup, kurang baik, dan buruk. Diharapkan dari penelitian ini memberikan kontribusi kepada perusahaan khususnya dalam penilaian kinerja karyawan, sehingga hasilnya menjadi lebih efektif. 


\section{METODOLOGI PENELITIAN}

Berikut tahapan yang dilakukan dalam penelitian:

1. Studi lapangan, pada tahapan awal ini dilakukan pengambilan terhadap data-data karyawan terlebih pada perusahaan.

2. Studi kepustakaan, selanjutnya di tahap studi kepustakaan, penulis melihat literatur yang berhubungan dengan indikator penilaian kinerja karyawan. Disini juga peneliti mengkaji tentang tahapan dalam metode Simple Additive Weighting (SAW).

3. Analisis masalah, pada tahap ini dilakukan perumusan terhadap masalah yang akan di bahas, khusus pada penelitian ini penulis menetapkan 15 data karyawan yang akan dijadikan sebagai alternatif keputusan dalam penilaian kinerja karyawan.

4. Pengujian metode, pada tahapan ini penulis menerapkan metode SAW dalam penyelesaian masalah, khususnya dalam perhitungan rating kinerja karyawan. Pada tahapan ini penulis melakukan tahapan dari metode SAW[17]-[19]:

a. Penetapan matrik keputusan $\mathrm{x}_{\mathrm{ij}}$.

b. Menghitung matrik ternormalisasi $\left(\mathrm{r}_{\mathrm{ij}}\right)$

c. Menghitung nilai preferensi $\left(\mathrm{v}_{\mathrm{i}}\right)$

5. Penetapan hasil penelitian, di tahap akhir penelitian penulis akan menetapkan peringkat terhadap rating kinerja karyawan. Rating kinerja karyawan akan di klasifikasikan kepada beberapa hasil yaitu karyawan yang memiliki kinerja sangat baik, baik, cukup, kurang baik dan buruk.

\section{HASIL DAN PEMBAHASAN}

Penilaian kinerja karyawan biasanya dilakukan pada periode tertentu, misalnya dilakukan pada 1 tahun masa kerja. Sehingga pada akhir tahun penilaian telah dilakukan oleh manajer. Hasil penilaian pada penelitian ini terbagi kedalam 5 keterangan, yaitu kinerja Sangat Baik $(0,80$ - 1,00), Baik $(0,70$ - 0,79), Cukup $(0,60$ - 0,69), Kurang Baik $(0,50-0,59)$ dan Buruk $(0,00-0,49)$. Ke 5 keterangan tersebut akan diberikan range penilaian, sehingga nilai preferensi dari metode SAW yang dihasilkan dapat merujuk pada range yang ditetapkan dan menghasilkan keterangan kinerja. Penetapan kriteria terhadap penilaian kinerja karyawan mutlak diperlukan, berikut pada tabel 1 merupakan data kriteria yang dijadikan dasar penilaian kinerja karyawan.

Tabel 1. Data Kriteria

\begin{tabular}{lll}
\hline Kriteria & Type & Weight \\
\hline Kualitas Kerja $\left(\mathrm{C}_{1}\right)$ & Benefit & 0.25 \\
Kerjasama $\left(\mathrm{C}_{2}\right)$ & Benefit & 0.20 \\
Kedisiplinan $\left(\mathrm{C}_{3}\right)$ & Benefit & 0.20 \\
Pengalaman $\left(\mathrm{C}_{4}\right)$ & Benefit & 0.15 \\
Keahlian $\left(\mathrm{C}_{5}\right)$ & Benefit & 0.10 \\
Pendidikan $(\mathrm{C} 6)$ & Benefit & 0.10 \\
\hline
\end{tabular}

Pada tabel 2 merupakan 15 data karyawan yang dijadikan sebagai alternatif untuk dinilai kinerjanya.

Tabel 2. Data Alternatif

\begin{tabular}{lllllll}
\hline Alternatif & $\mathrm{C}_{1}$ & $\mathrm{C}_{2}$ & $\mathrm{C}_{3}$ & $\mathrm{C}_{4}$ & $\mathrm{C}_{5}$ & $\mathrm{C}_{6}$ \\
\hline Triani $\left(\mathrm{A}_{1}\right)$ & Good & Good & Very Good & 2 tahun & Very Good & Strata I \\
Arista $\left(\mathrm{A}_{2}\right)$ & Very Good & Good & Very Good & 3 tahun & Very Good & Diploma \\
Chairunisah $\left(\mathrm{A}_{3}\right)$ & Very Good & Good & Very Good & 1 tahun & Good & Magister \\
M. Rifky $\left(\mathrm{A}_{4}\right)$ & Good & Good & Very Good & 5 tahun & Very Good & Diploma \\
Aldyan $\left(\mathrm{A}_{5}\right)$ & Good & Good & Good & 3 tahun & Good & Diploma \\
Santang $\left(\mathrm{A}_{6}\right)$ & Very Good & Good & Good & 6 tahun & Good & Diploma \\
Joko $\left(\mathrm{A}_{7}\right)$ & Good & Very Good & Very Good & 3 tahun & Pretty Good & Diploma \\
Fahmy $\left(\mathrm{A}_{8}\right)$ & Good & Good & Very Good & 2 tahun & Very Good & Strata I \\
M Ridwan $\left(\mathrm{A}_{9}\right)$ & Good & Very Good & Good & 3 tahun & Poorly & Strata I \\
Susilawati $\left(\mathrm{A}_{10}\right)$ & Good & Very Good & Very Good & 2 tahun & Good & Magister \\
Desy $\left(\mathrm{A}_{11}\right)$ & Very Good & Good & Very Good & 2 tahun & Good & Diploma \\
Eko $\left(\mathrm{A}_{12}\right)$ & Good & Very Good & Very Good & 4 tahun & Very Good & Diploma \\
Mariani $\left(\mathrm{A}_{13}\right)$ & Good & Good & Pretty Good & 5 tahun & Good & Diploma \\
Rahel $\left(\mathrm{A}_{14}\right)$ & Good & Very Good & Good & 2 tahun & Very Good & Strata I \\
Rony $\left(\mathrm{A}_{15}\right)$ & Very Good & Good & Poorly & 3 tahun & Very Good & Strata I \\
\hline
\end{tabular}

Penerapan metode SAW dalam menghitung nilai kinerja karyawan dapat memiliki beberapa tahapan. Tahapan awal menentukan kriteria, bobot (tabel 1), dan alternatif (tabel 2). Selanjutnya menentukan matrik keputusan, namun pada tabel 2 terlihat data-data yang bersifat linguistik sehingga harus dilakukan pembobotan 
ISSN 2614-5278 (media cetak), ISSN 2548-8368 (media online)

Available Online at https://ejurnal.stmik-budidarma.ac.id/index.php/mib DOI 10.30865/mib.v5i3.3103

terhadap nilai data pada tiap tiap kriteria tersebut. Pada tabel 3 dan 4 berikut merupakan klasifikasi dari bobot pada kriteria.

Tabel 3. Pembobotan nilai kriteria $\mathrm{C}_{1}, \mathrm{C}_{2}, \mathrm{C}_{3}, \mathrm{C}_{5}$

\begin{tabular}{ll}
\hline Description & Value \\
\hline Very Good & 5 \\
Good & 4 \\
Pretty Good & 3 \\
Poorly & 2 \\
Not Good & 1 \\
\hline
\end{tabular}

Tabel 4. Pembobotan nilai kriteria $\mathrm{C}_{1}, \mathrm{C}_{2}, \mathrm{C}_{3}, \mathrm{C}_{5}$

\begin{tabular}{ll}
\hline Description & Value \\
\hline Magister & 3 \\
Strata I & 2 \\
Diploma & 1 \\
\hline
\end{tabular}

Dari tabel 3 dan tabel 4 maka rating kecocokan antara alternatif dan kriteria dapat diperoleh, yang dapat dilihat pada tabel 5 berikut ini.

Tabel 5. Data Rating Kecocokan

\begin{tabular}{lllllll}
\hline Alternatif & $\mathrm{C}_{1}$ & $\mathrm{C}_{2}$ & $\mathrm{C}_{3}$ & $\mathrm{C}_{4}$ & $\mathrm{C}_{5}$ & $\mathrm{C}_{6}$ \\
\hline Triani $\left(\mathrm{A}_{1}\right)$ & 4 & 4 & 5 & 2 & 5 & 2 \\
Arista $\left(\mathrm{A}_{2}\right)$ & 5 & 4 & 5 & 3 & 5 & 1 \\
Chairunisah $\left(\mathrm{A}_{3}\right)$ & 5 & 4 & 5 & 1 & 4 & 3 \\
M. Rifky $\left(\mathrm{A}_{4}\right)$ & 4 & 4 & 5 & 5 & 5 & 1 \\
Aldyan $\left(\mathrm{A}_{5}\right)$ & 4 & 4 & 4 & 3 & 4 & 1 \\
Santang $\left(\mathrm{A}_{6}\right)$ & 5 & 4 & 4 & 6 & 4 & 1 \\
Joko $\left(\mathrm{A}_{7}\right)$ & 4 & 5 & 5 & 3 & 3 & 1 \\
Fahmy $\left(\mathrm{A}_{8}\right)$ & 4 & 4 & 5 & 2 & 5 & 2 \\
M Ridwan $\left(\mathrm{A}_{9}\right)$ & 4 & 5 & 4 & 3 & 2 & 2 \\
Susilawati $\left(\mathrm{A}_{10}\right)$ & 4 & 5 & 5 & 2 & 4 & 3 \\
Desy $\left(\mathrm{A}_{11}\right)$ & 3 & 4 & 5 & 2 & 4 & 1 \\
Eko $\left(\mathrm{A}_{12}\right)$ & 4 & 5 & 5 & 4 & 5 & 1 \\
Mariani $\left(\mathrm{A}_{13}\right)$ & 4 & 4 & 3 & 5 & 4 & 1 \\
Rahel $\left(\mathrm{A}_{14}\right)$ & 4 & 5 & 4 & 2 & 5 & 2 \\
Rony $\left(\mathrm{A}_{15}\right)$ & 5 & 4 & 2 & 3 & 5 & 2 \\
\hline
\end{tabular}

Tahapan selanjutnya pada penerapan SAW, menentukan matriks keputusan yang didasarkan pada tabel 5. Berikut merupakan matriks keputusan.

Tabel 6. Matriks Keputusan

$$
\mathrm{X}_{\mathrm{ij}}=\left|\begin{array}{cccccc}
4 & 4 & 5 & 2 & 5 & 2 \\
5 & 4 & 5 & 3 & 5 & 1 \\
5 & 4 & 5 & 1 & 4 & 3 \\
4 & 4 & 5 & 5 & 5 & 1 \\
4 & 4 & 4 & 3 & 4 & 1 \\
5 & 4 & 4 & 6 & 4 & 1 \\
4 & 5 & 5 & 3 & 3 & 1 \\
4 & 4 & 5 & 2 & 5 & 2 \\
4 & 5 & 4 & 3 & 2 & 2 \\
4 & 5 & 5 & 2 & 4 & 3 \\
3 & 4 & 5 & 2 & 4 & 1 \\
4 & 5 & 5 & 4 & 5 & 1 \\
4 & 4 & 3 & 5 & 4 & 1 \\
4 & 5 & 4 & 2 & 5 & 2 \\
5 & 4 & 2 & 3 & 5 & 2
\end{array}\right|
$$

Setelah diperoleh matriks keputusan $\left(\mathrm{x}_{\mathrm{ij}}\right)$, kemudian menghitung matriks ternormalisasi. Tujuan dari matriks ternormalisasi ini menentukan perbandingan nilai xij, alternatif dengan yang terbaik dari tiap kriteria dari alternatif pertama hingga terakhir. Untuk menormalisasi matriks keputusan membutuhkan persamaan 1 dan 2. 
JURNAL MEDIA INFORMATIKA BUDIDARMA

Volume 5, Nomor 3, Juli 2021, Page 1068-1072

ISSN 2614-5278 (media cetak), ISSN 2548-8368 (media online)

Available Online at https://ejurnal.stmik-budidarma.ac.id/index.php/mib DOI 10.30865/mib.v5i3.3103

$r_{i j}=\frac{X i j}{\max _{i} X_{i j}} \quad$ untuk kriteria keuntungan (1)

$r_{i j}=\frac{\min _{i} X_{i j}}{X i j} \quad$ Untuk kriteria biaya

Hasil dari perhitungan ini diperoleh matriks ternormalisasi $\left(\mathrm{r}_{\mathrm{ij}}\right)$

Tabel 7. Matriks Ternormalisasi $\left(\mathrm{r}_{\mathrm{ij}}\right)$

$\mathrm{r}_{\mathrm{ij}}=\left|\begin{array}{cccccc}0.80 & 0.80 & 1.00 & 0.33 & 1.00 & 0.67 \\ 1.00 & 0.80 & 1.00 & 0.50 & 1.00 & 0.33 \\ 1.00 & 0.80 & 1.00 & 0.17 & 0.80 & 1.00 \\ 0.80 & 0.80 & 1.00 & 0.83 & 1.00 & 0.33 \\ 0.80 & 0.80 & 0.80 & 0.50 & 0.80 & 0.33 \\ 1.00 & 0.80 & 0.80 & 1.00 & 0.80 & 0.33 \\ 0.80 & 1.00 & 1.00 & 0.50 & 0.60 & 0.33 \\ 0.80 & 0.80 & 1.00 & 0.33 & 1.00 & 0.67 \\ 0.80 & 1.00 & 0.80 & 0.50 & 0.40 & 0.67 \\ 0.80 & 1.00 & 1.00 & 0.33 & 0.80 & 1.00 \\ 0.60 & 0.80 & 1.00 & 0.33 & 0.80 & 0.33 \\ 0.80 & 1.00 & 1.00 & 0.67 & 1.00 & 0.33 \\ 0.80 & 0.80 & 0.60 & 0.83 & 0.80 & 0.33 \\ 0.80 & 1.00 & 0.80 & 0.33 & 1.00 & 0.67 \\ 1.00 & 0.80 & 0.40 & 0.50 & 1.00 & 0.67\end{array}\right|$

Tahapan akhir dari metode Simple Additive Weighting (SAW) yaitu menentukan nilai preferensi $\left(\mathrm{v}_{\mathrm{i}}\right)$ dengan menggunakan persamaan 3 sebagai berikut.

$v_{i}=\sum_{j=1}^{n} w_{j} \cdot r_{i j}$

Hasil akhir, dari perhitungan preferensi, dapat dilihat pada tabel 7.

Tabel 8. Hasil Preferensi

\begin{tabular}{llll}
\hline Alternatif & $\mathrm{Vi}$ & Rangking & Keterangan Kinerja \\
\hline Triani $\left(\mathrm{A}_{1}\right)$ & 0.777 & 7 & Baik \\
Arista $\left(\mathrm{A}_{2}\right)$ & 0.818 & 4 & Sangat Baik \\
Chairunisah $\left(\mathrm{A}_{3}\right)$ & 0.815 & 6 & Sangat Baik \\
M. Rifky $\left(\mathrm{A}_{4}\right)$ & 0.818 & 5 & Sangat Baik \\
Aldyan $\left(\mathrm{A}_{5}\right)$ & 0.708 & 14 & Baik \\
Santang $\left(\mathrm{A}_{6}\right)$ & 0.833 & 1 & Sangat Baik \\
Joko $\left(\mathrm{A}_{7}\right)$ & 0.768 & 10 & Baik \\
Fahmy $\left(\mathrm{A}_{8}\right)$ & 0.777 & 8 & Baik \\
M Ridwan $\left(\mathrm{A}_{9}\right)$ & 0.742 & 11 & Baik \\
Susilawati $\left(\mathrm{A}_{10}\right)$ & 0.83 & 3 & Sangat Baik \\
Desy $\left(\mathrm{A}_{11}\right)$ & 0.673 & 15 & Cukup \\
Eko $\left(\mathrm{A}_{12}\right)$ & 0.833 & 2 & Sangat Baik \\
Mariani $\left(\mathrm{A}_{13}\right)$ & 0.718 & 13 & Baik \\
Rahel $\left(\mathrm{A}_{14}\right)$ & 0.777 & 9 & Baik \\
Rony $\left(\mathrm{A}_{15}\right)$ & 0.732 & 12 & Baik \\
\hline
\end{tabular}

Dari tabel 8 terdapat 6 karyawan dengan kinerja yang Sangat Baik, 8 karyawan dengan kinerja Baik, dan 1 karyawan dengan kinerja Cukup. Bila di gambarkan dengan menggunakan grafik, dapat dilihat seperti pada gambar berikut ini.

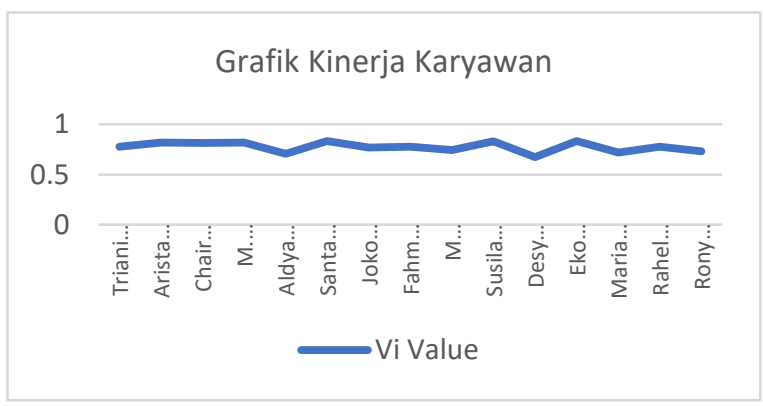

Gambar 1. Grafik Kinerja Karyawan 
Hasil akhir yang terlihat pada tabel 8, dapat digunakan oleh manager sebagai rekomendasi hasil penilaian kinerja karyawan. Predikat kinerja ini dapat juga dijadikan acuan dalam pemberian reward kepada karyawan yang memiliki kinerja Sangat Baik dan Baik.

\section{KESIMPULAN}

Pengolahan data dalam menentukan kinerja karyawan sangat diperlukan. Hal ini sangat dibutuhkan manager dalam memberikan evaluasi terhadap hasil kerja karyawan dalam periode waktu tertentu. Hasil penelitian dengan menerapkan metode Simple Additive Weighting (SAW) mampu memberikan pemeringkatan terhadap kinerja karyawan. Dalam tahapan proses yang dilakukan, metode SAW sangat sederhana namun dapat menghasilkan penilaian yang dijadikan dasar perhitungan kinerja karyawan.

\section{REFERENCES}

[1] Efraim Turban and Jay E. Aronson, Decision Support System and Intelligent Systems. 2001.

[2] G.-H. Tzeng and J.-J. Huang, Fuzzy Multiple Objective Decision Making. CRC Press, 2014.

[3] D. Nofriansyah and S. Defit, Multi Criteria Decision Making (MCDM) pada Sistem Pendukung Keputusan. 2018.

[4] D. Nofriansyah, Multi Criteria Decision Making (MCDM) Pada Sistem Pendukung Keputusan. Yogyakarta: CV.Budi Utama, 2017.

[5] D. Siregar et al., "Multi-Attribute Decision Making with VIKOR Method for Any Purpose Decision," in Journal of Physics: Conference Series, 2018, vol. 1019, no. 1.

[6] Mesran, R. K. Hondro, M. Syahrizal, A. P. U. Siahaan, R. Rahim, and Suginam, "Student Admission Assessment using Multi-Objective Optimization on the Basis of Ratio Analysis (MOORA)," J. Online Jar. COT POLIPT, vol. 10, no. 7 , pp. 1-6, 2017.

[7] A. Yanie et al., "Web Based Application for Decision Support System with ELECTRE Method," J. Phys. Conf. Ser., vol. 1028, no. 1, 2018.

[8] Supriyanto, Mesran, D. Kusnady, Weny, and Murtopo, "Implementation of Computer-Based Systems in Efficient Credit Acceptance Decisions Applying the Additive Ratio Assessment (ARAS) Method," in 2nd International Conference on Advance \& Scientific Innovation, 2019, vol. 1424, no. 1.

[9] D. Siregar et al., "Multi-Attribute Decision Making with VIKOR Method for Any Purpose Decision," in 1st International Conference on Green and Sustainable Computing (ICoGeS) 2017, 2018, vol. 1019, no. 1.

[10] M. Mesran et al., "The VIKOR Method to Support the Effectiveness of Decisions in Determining Work Incentive Recipients," J. Phys. Conf. Ser., vol. 1175, p. 012043, 2019.

[11] S. Sutarno, M. Mesran, S. Supriyanto, Y. Yuliana, and A. Dewi, "Implementation of Multi-Objective Optimazation on the Base of Ratio Analysis (MOORA) in Improving Support for Decision on Sales Location Determination," in 2nd International Conference on Advance \& Scientific Innovation, 2019, vol. 1424, no. 1.

[12] Khairul;, M. Simaremare, A. Putera, and U. Siahaan, "Decision Support System in Selecting The Appropriate Laptop Using Simple Additive Weighting," Int. J. Recent TRENDS Eng. Res., vol. 2, no. 12, pp. 215-222, 2016.

[13] M. D. L. Siahaan, Elviwani, A. B. Surbakti, A. H. Lubis, and A. P. U. Siahaan, "Implementation of Simple Additive Weighting Algorithm in Particular Instance,” Int. J. Sci. Res. Sci. Technol., vol. 3, no. 6, pp. 442-447, 2017.

[14] V. Podvezko, "The Comparative Analysis of MCDA Methods SAW and COPRAS," Inz. Ekon. Econ., vol. 22, no. 2, pp. 134-146, 2011.

[15] R. Y. Simanullang, Melisa, and Mesran, "Sistem Pendukung Keputusan Penerima Bantuan Covid-19 Menggunakan Metode Simple Additive Weighting (SAW)," TIN Terap. Inform. Nusant., vol. 1, no. 9, pp. 2-9, 2021.

[16] M. R. Ramadhan, M. K. Nizam, and Mesran, "Penerapan Metode SAW (Simple Additive Weighting) Dalam Pemilihan Siswa-Siswi Berprestasi Pada Sekolah SMK Swasta Mustafa," TIN Terap. Inform. Nusant., vol. 1, no. 9, pp. 459-471, 2021.

[17] S. H. Sahir, R. Rosmawati, and K. Minan, "Simple Additive Weighting Method to Determining Employee Salary Increase Rate,” Int. J. Sci. Res. Sci. Technol., vol. 3, no. 8, pp. 42-48, 2017.

[18] T. Limbong et al., Sistem Pendukung Keputusan: Metode \& Implementasi. Medan: Yayasan Kita Menulis, 2020.

[19] I. J. T. Situmeang, S. Hummairoh, S. M. Harahap, and Mesran, "Application of SAW ( Simple Additive Weighting ) for the Selection of Campus Ambassadors," IJICS (International J. Informatics Comput. Sci., vol. 5, no. 1, pp. 21-28, 2021. 